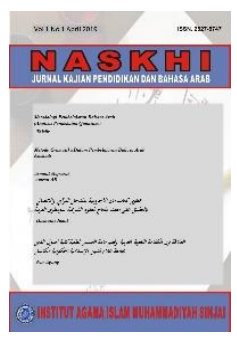

NASKHI

Jurnal Kajian Pendidikan dan Bahasa Arab

Volume 3, No. 1, 2021

ISSN (print) : 2527-5747

ISSN (online) : 2716-3369

Homepage : https://journal.iaimsinjai.ac.id/index.php/naskhi

\title{
MEMAHAMI PERBEDAAN ANTARA BAHASA ARAB FUSHAH DAN 'AMMIYAH
}

\author{
Amran AR ${ }^{1}$, Takdir $^{2}$, Ahmad Munawwir ${ }^{3}$, Nurlatifah $^{4}$ \\ ${ }^{1}$ Institut Agama Islam Muhammadiyah, Sinjai \\ ${ }^{2}$ Institut Agama Islam Muhammadiyah, Sinjai \\ ${ }^{3}$ Universitas Islam Negeri Alauddin, Makassar \\ ${ }^{4}$ Institut Agama Islam Muhammadiyah, Sinjai \\ E-mail: amran.iaimsinjai@gmail.com, Tlp:+6281389013838
}

\begin{abstract}
Abstrak
Bahasa Arab Fushah dan 'Ammiyah merupakan bahasa Arab yang bersumber dari bahasa Smit, penggunaan bahasa Fushah di dapatkan pada kitab suci al-Qur'an, al-Hadis dan buku-buku ilmiah lainnya, sedangkan bahasa 'Ammiyah bisa didapatkan pada ungkapan yang dipergunakan seharihari sebagai alat komunikasi bangsa Arab. Penelitian ini menggunakan penelitian kepustakaan (library research), penelitian ini berfokus pada pengumpulan data yang berkaitan dengan kepustakaan melalui bacaan dan catatan untuk mengolah bahan penelitian. Pra Islam, masyarakat Arab mengenal stratifikasi kefasihan bahasa. Kabilah yang dianggap paling baik bahasa Arabnya dibanding yang lain adalah Quraisy yang dikenal sebagai surat al-Arab (pusatnya masyarakat Arab). Kefasihan bahasa Quraisy ditunjang oleh tempat tinggal mereka yang secara geografis berjauhan dengan negara-negara bangsa non-Arab dari segala penjuru. Bahasa 'Ammiyah adalah "bahasa dalam penyimpangan" (lughat fi al-lahn) setelah sebelumnya merupakan fenomena dalam penyimpangan bahasa. Secara perlahan tapi pasti bahasa 'Ammiyah terus berkembang hingga menjelma sebagai bahasa yang otonom dengan kaidah dan ciri-cirinya sendiri. Bahasa 'Ammiyah di negeri-negeri (taklukan) Islam awalnya adalah lahn yang sederhana dan masih labil karena masyarakatnya masih memiliki watak bahasa Arab yang genuin. Karena itu, di awal kemunculannya bahasa 'Ammiyah di kalangan masyarakat masih mempunyai rentangan antara yang lebih dekat dengan bahasa baku (Fushah) sampai pada yang jauh darinya.
\end{abstract}

\section{Kata Kunci: Bahasa Arab, Fushah, 'Ammiyah}

\section{Pendahuluan}

Perkembangan pembelajaran bahasa di era 4.0 begitu berkembang selaras dengan perkembangan teknologi yang begitu cepat. Berbagai informasi pengetahuan baik di bidang teknik, ekonomi, psikologi dan seni begitu mudah didapatkan begitupun dengan ilmu yang berkaitan dengan bahasa Arab, dan berbagai ilmu tersebut bisa di dapatkan dalam buku-buku berbahasa Arab.(Amran AR \& Takdir, 2020). Pembelajaran bahasa Arab sangatlah dibutuhkan suatu pendekatan yang baru agar pembelajaran bahasa Arab terasa lebih menyenangkan (Takdir, 2019) Bahasa merupakan alat komunikasi antara satu bangsa dengan bangsa lain. Bangsa Arab merupakan ba ngsa yang sangat fanatik terhadap bahasanya, sehingga dengan penuh keyakinan mereka mengatakan bahwa al-Qur'an di turunkan dengan menggunakan bahasa Arab, karena pada hakekatnya Nabi Muhammad SAW di lahirkan di bangsa Arab. Kecintaan orang Arab akan bahasanya ini, membuat bahasa Arab begitu cepat berkembang. Bahasa Arab merupakan salah satu rumpun bahasa Semit, dipergunakan oleh suku Arab yang tinggal di Semenanjung Jazirah Arab. Masyarakat pra Islam terdiri dari berbagai kabilah dan sejumlah dialek bahasa yang berbeda satu dengan lainnya, perbedaan tersebut dilandasi atas kondisi dan perbedaan dari masing-masing kabilah (Wafi, 1983). 


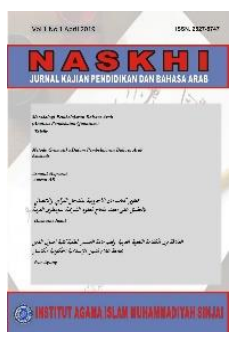

\section{NASKHI}

\section{Jurnal Kajian Pendidikan dan Bahasa Arab \\ Volume 3, No. 1, 2021}

ISSN (print) : 2527-5747

ISSN (online) : 2716-3369

Homepage : https://journal.iaimsinjai.ac.id/index.php/naskhi

Bahasa Arab merupakan Bahasa resmi kedua dengan banyaknya negara menggunakannya, baik pada percakapan sehari-hari, maupun pertemuan tinggat dunia. Berbagai pendapat tentang sejarah permulaan munculnya bahasa Arab, pendapat yang paling klasik menyebutkan bahwa bahasa Arab sudah ada sejak zaman Nabi Adam as, dasar dari pendapat ini adalah firman Allah SWT dalam Alquran surah Al-Baqarah ayat 31;

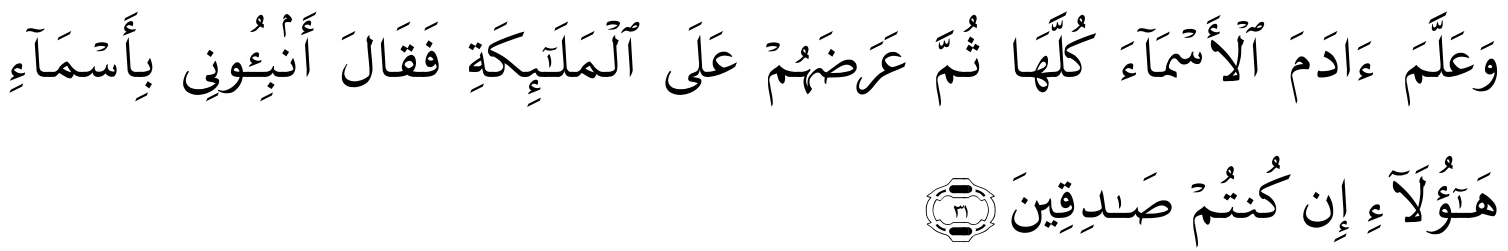

Terjemahannya:

dan Dia mengajarkan kepada Adam Nama-nama (benda-benda) seluruhnya, kemudian mengemukakannya kepada Para Malaikat lalu berfirman: "Sebutkanlah kepada-Ku nama benda-benda itu jika kamu mamang benar orang-orang yang benar!"

Bahasa Arab mempunyai dua dialek yaitu bahasa Arab Fushah dan Arab 'Ammiyah. Bahasa Arab Fushahh merupakan bahasa yang digunakan dalam Al-Qura'n, al- Hadis dan pada karya tulis ilmiah. Bahasa Arab Fushahh sudah menjadi bahasa internasional yang diresmikan pada 18 Desember 1973 oleh UNESCO (United Nation Education, Scientific and Cultural Organization). Kemudian penetapan tanggal tersebut dijadikan sebagai hari bahasa Arab sedunia. Oleh karena itu bahasa Arab Fushahh ragam standar inilah yang kemudian digunakan di negara-negara Arab dan mayoritas kaum muslimin di seluruh dunia. Secara umum bahasa ini dapat diklasifikasikan dalam dua tingkatan, yaitu bahasa Arab klasik (classical Arabic) yang digunakan dalam bahasa Alquran dan bahasa Arab standar modern (modern standard Arabic) yang digunakan dalam bahasa ilmiah.

Adapun bahasa Arab Amiyah adalah bahasa yang sering digunakan dalam aktivitas sehari hari yang berbentuk informal atau nonformal. Bahasa ini lebih sering disebut dengan bahasa pasaran. Menurut Emil Badi' Ya'qub, bahasa Amiyah - dikenal juga dengan al-lahjah - adalah bahasa yang digunakan dalam urusan biasa (tidak resmi) dan yang diterapkan dalam keseharian (bahasa pasaran). Bahasa Arab Amiyah tidak dapat dilepaskan dari bahasa Arab Fushah, selain itu bahasa Arab ini pun tidak sepenuhnya sesuai dengan kaidah atau tata bahasa Arab yang resmi. Bahasa Arab Amiyah di setiap negara juga mempunyai berbagai versi sesuai dengan negara dan daerah yang menggunakan bahasa tersebut, sehingga kita dapat menjumpai ada bahasa Amiyah Saudi Arabia, Amiyah Sudan, dan Amiyah Mesir dan sebagainya. Bahasa ini tidak lain adalah bahasa yang hidup di negara dan daerah tersebut serta digunakan dalam komunikasi sehari-hari. Adapun istilah-istilah lain yang sering digunakan oleh para ahli bahasa untuk menyebut jenis bahasa Amiyah ini adalah al-Lahjah as-Syai'ah, al-Lughah al-Muhakkiyah, al-Lughah al-'Arabiyah al-'Ammiyah, al-Lahjah al-'Ammiyah dan ada pula yang menyebutnya dengan istilah lughatusy Sya'b.

Perbedaan mendasar antara Fushah dan Amiyah terdapat pada kepatuhan terhadap kaidahkaidah kebahasaan. Bahasa Arab Fushah sangat memperhatikan kaidah-kaidah nahwu dan sharf, sedangkan bahasa Arab Amiyah tidak memperhatikan hal tersebut. Oleh karena itu penggunaan bahasa Arab Fushah dan Amiyah digunakan dalam forum yang berbeda pula. Perbedaan lainnya di antara bahasa Arab Fushah dan Amiyah adalah dari segi pengucapan dan logat. Tidak jarang bahasa Amiyah ini masih sering muncul ketika penutur asli berkomunikasi menggunakan bahasa Arab Fushah karena memang adanya kebiasaan penggunaan bahasa Amiyah dalam keseharian dan adanya kedekatan/kemiripan bahasa Amiyah dengan bahasa Fushah. 


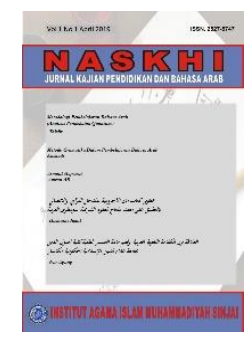

NASKHI

Jurnal Kajian Pendidikan dan Bahasa Arab

Volume 3, No. 1, 2021

ISSN (print) : 2527-5747

ISSN (online) : 2716-3369

Homepage : https://journal.iaimsinjai.ac.id/index.php/naskhi

\section{Metode}

\subsection{Jenis Penelitian}

Penelitian ini menggunakan penelitian kepustakaan (library research), penelitian ini berfokus pada pengumpulan data yang berkaitan dengan kepustakaan melalui bacaan dan catatan untuk mengolah bahan penelitian. (Zed, 2008: 3). Mahmud menjelaskan mengenai penelitian pustaka melalui bukunya Metode penelitian Pendidikan mengatakan kepustakaan adalah penelitian yang terlaksana melalui buku, majalah dan sumber bacaan lain untuk mengumpulkan data. (Mahmud, 2011: 31). Devinisi dari penelitian ini menjelaskan bahwa setelah melakukan pengumpulan berbagai data kemudian melaksanakan tahap-tahap penelitian berkaitan dengan penelitian tersebut.

\subsection{Pendekatan Penelitian}

Penelitian ini menggunakan pendekatan kualitatif. Moleong mengemukakan beberapa karakter dan ciri penelitian kualitatif yaitu berlatar alamiah, manusia sebagai alat (instrumen), menggunakan metode kualitatif, analisa data secara induktif, teori berdasarkan data, data bersifat deskriptif, adanya batas yang ditentukan oleh focus. (Moleong, 2009: 8). Pendekatan kualitatif digunakan untuk mendapatkan data yang mendalam, suatu data yang mengandung makna. (Sugiyono, 2012: 15)

\subsection{Sumber Data}

Penelitian pustaka menggunakan sumber data berbasis kepustakaan dari berbagai literature seperti buku, jurnal, artikel maupun tulisan dari internet, oleh karenanya sumber data dibedakan dengan sumber data primer dan sukender. Sumber primer adalah sumber data pokok yang langsung dikumpulkan peneliti dari objek penelitian, sedangkan sumber data sekunder adalah sumber data tambahan yang menurut peneliti menunjang data pokok. (Mahmud, 2011: 152)

\subsection{Teknik Analisis Data}

Pertama; Analisis konten atau Kajian isi yang merupakan metodologi yang menggunakan seperangkat prosedur untuk menarik kesimpulan yang sahih dari sebuah buku atau dokumen. (Moleong, 2009: 220), sedangkan Harold D. Lasswell menyatakan bahwa analisis konten adalah penelitian yang bersifat pembahasan mendalam terhadap isi suatu informasi tertulis atau tercetak dalam mediamassa. (Rinaldy, 20 15).

Kedua; Analisis Induktif merupakan suatu analysis yang berdasar dari data yang diperoleh, kemudian dikembangkan pola hubungan tertentu atau menjadi hipotesis, selanjutnya mencarikan data dari berbagai sumber lain sesuai data yang dibutuhkan sehingga hipotesis diterima dan hipotesis tesebut berkembang menjadi teori. (Sugiyono, 2012: 335)

\section{Hasil dan Pembahasan}

\subsection{Pengertian bahasa Arab Fushah dan'Ammiyah}

Menurut Emil Badi' Ya'qub, bahasa Arab Fushah adalah bahasa al Qur-an, karya tulis ilmiah, bahasa pada konfrensi antara bangsa. Bahasa Arab Fushah ini juga biasa digunakan dalam bahasa pengantar resmi di berbagai kampus yang ada di negara Arab maupun kampus yang mempelajari bahasa Arab. Arab Fushah dan 'Ammiyah merupakan dua corak bahasa yang berbeda namun hakekatnya satu. (Ya'kub, 1982: 144). Bahasa Arab Fushah merupakan bahasa Arab yang dapat dipahami oleh seluruh bangsa Arab maupun non Arab yang mempelajari bahasa tersebut dan dapat digunakan di negara manapun. Azhar Arsyad mengemukakan bahasa Arab 'Ammiyah dikenal dengan bahasa Arab yaumiah (harian) bahkan suqiyah (pasaran), dan ada juga yang menyebutnya dengan bahasa Arab kolukwial atau dialek lisan setempat. (Arsyad, 2003: 4) 


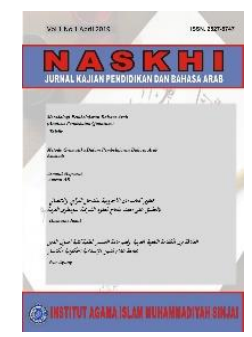

NASKHI

Jurnal Kajian Pendidikan dan Bahasa Arab

Volume 3, No. 1, 2021

ISSN (print) : 2527-5747

ISSN (online) : 2716-3369

Homepage : https://journal.iaimsinjai.ac.id/index.php/naskhi

Arab yang terbentang dari teluk persia hingga laut mediteranian terdapat aneka ragam dialek âmiyah/darijah (ragam non-standar) yang masing-masing memiliki perbedaan fonetik, kosakata, dan strukturnya. Pada abad 19 Masehi, para ilmuan bahasa membagi dialek âmiyah ke dalam lima kelompok (Al-Wafi, tt: 143), yaitu :

1. Dialek Hijâziyah-Najdiyyah; dialek ini digunakan di Hijâz, Najed, dan Yaman.

2. Dialek Syria; berkembang di Syria, Lebanon, Palestina, dan Timur Yordania.

3. Dialek Irak; digunakan di negara Irak.

4. Dialek Mesir dapat kita temui di dua negara, yaitu Mesir dan Sudan.

5. Dialek Maghrîbiyah; banyak digunakan oleh penduduk Afrika sebelah barat.

\subsection{Sejarah Munculnya Bahasa Arab Fushah dan Amiyah}

Pra Islam, masyarakat Arab mengenal stratifikasi kefasihan bahasa. Kabilah yang dianggap paling baik bahasa Arabnya dibanding yang lain adalah Quraisy yang dikenal sebagai surat alArab (pusatnya masyarakat Arab). Kefasihan bahasa Quraisy ditunjang oleh tempat tinggal mereka yang secara geografis berjauhan dengan negara-negara bangsa non-Arab dari segala penjuru. Dibawah kefasihan Quraisy adalah bahasa kabilah Tsaqif, Hudzail, Khuza'ah, Bani Kinanah, Ghathfan, Bani Asad, dan Bani Tamim, menyusul kemudian kabilah Rabi'ah, Lakhm, Judzam, Ghassan, Iyadh, Qadha'ah, dan Arab Yaman yang bertetangga dekat dengan Persia, Romawi, dan Habasyah.

Kefasihan berbahasa itu terus terjaga hingga meluasnya Islam ke luar jazirah dan masyarakat Arab mulai berinteraksi dengan masyarakat dari suku lain. Proses interaksi dan berbagai transaksi sosial lainnya itu berpengaruh antara bahasa yang digunakan. Masyarakat 'Ajam belajar berbahasa Arab dan masyarakat Arab mulai mengenal bahasa mereka. Intensitas interaksi tersebut lambat laun mulai berimplikasi pada penggunaan bahasa Arab yang mulai bercampur dengan beberapa kosakata asing, baik dengan atau tanpa proses arabisasi (ta'rib). Pertukaran pengetahuan antar mereka juga berpengaruh pada pertambahan khazanah bahasa Arab khususnya menyangkut hal-hal yang sebelumnya tidak diketahui masyarakat Arab ketika hidup terisolasi dari bangsa lain. Masyarakat nonArab juga kerap melakukan kesalahan dalam menggunakan bahasa Arab. Fenomena ini kemudian makin meluas melalui transaksi sosial, misalnya dalam aktivitas ekonomi di pasar-pasar terutama sejak abad ke-5 $\mathrm{H}$.

Fenomena penyimpangan bahasa (lahn) adalah cikal bakal lahirnya bahasa 'Ammiyah. Istilah lahn ini dikarenakan awalnya pada kesalahan dan ketidaktaatan pada i'rab, yaitu perubahan bunyi akhir kata karena perubahan kedudukannya dalam kalimat. Benih-benih lahn mulai muncul sejak zaman Nabi Muhammad SAW berupa perbedaan lahjah (logat cara berbicara) di kalangan sahabat. (Al-Rafi'I, 1974: 234)

Bahasa Arab "Ammiyah adalah bahasa yang "menyalahi” kaidah-kaidah orisinil bahasa Fushah. Dengan kata lain, bahasa "Ammiyah adalah "bahasa dalam penyimpangan" (lughat fi al-lahn) setelah sebelumnya merupakan fenomena dalam penyimpangan bahasa. Secara perlahan tapi pasti bahasa 'Ammiyah terus berkembang hingga menjelma sebagai bahasa yang otonom dengan kaidah dan ciri-cirinya sendiri. Bahasa 'Ammiyah di negeri-negeri (taklukan) Islam awalnya adalah lahn yang sederhana dan masih labil karena masyarakatnya masih memiliki watak bahasa Arab yang genuin. Karena itu, di awal kemunculannya bahasa 'Ammiyah di kalangan masyarakat masih mempunyai rentangan antara yang lebih dekat dengan bahasa baku (Fushah) sampai pada yang jauh darinya. Contoh daerah yang memiliki bahasa yang masih sangat dekat dengan bahasa baku itu sampai abad ke-3 H antara lain negeri Hijaz, Basrah, dan Kufah. Selanjutnya bahasa 'Ammiyah mulai menyebar di beberapa tempat semisal Syam, Mesir, dan Sawad. Di beberapa tempat itu bahasa Arab Fushah sudah menerima kosakata serapan dari Persia, Romawi, Qibtiyah, dan Nabthiyah dalam 


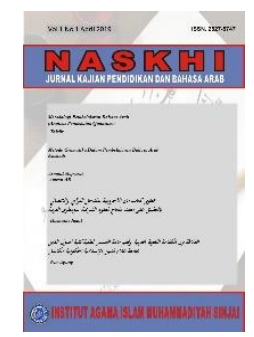

NASKHI

Jurnal Kajian Pendidikan dan Bahasa Arab

Volume 3, No. 1, 2021

ISSN (print) : 2527-5747

ISSN (online) : 2716-3369

Homepage : https://journal.iaimsinjai.ac.id/index.php/naskhi

jumlah yang cukup besar. Karena itu bahasa masyarakat mulai rusak dalam ukuran yang signifikan. Masyarakat mulai mencampur adukkan bahasa asli mereka dengan bahasa-bahasa serapan tanpa melakukan pemilihan. Di antara kosakata serapan yang paling banyak diambil adalah kata benda (asma), sedangkan kata-kata ajektiva sedikit saja yang diadopsi. Banyaknya pengadopsian kata benda itu karena intensitas pemakaiannya lebih tinggi dibanding dengan jenis kata yang lain. (Al-Rafi'I, 1974: 25)

\subsection{Faktor-faktor yang Mendorong Munculnya Bahasa Arab ‘Ammiyah}

Ada beberapa faktor yang mendorong lahirnya bahasa Arab Amiyah, diantaranya adalah sebagai berikut:

Faktor pertama adalah masalah geografis. Bahasa Arab pada awalnya digunakan oleh masyarakat yang berdiam di Semenanjung Arab atau Jazirah Arab. Sebagian besar wilayah Semenanjung Arab ini terdiri atas gurun dan gunung batu sehingga letak perkampungan satu kabilah dengan kabilah lain berjauhan. Bahasa Arab sebagai alat komunikasi masyarakat penghuni wilayah itupun menjadi beragam. Sejak lama orang Arab tinggal di penjuru Semenanjung yang sangat luas. Mereka hidup dalam kabilah-kabilah yang berlainan pada wilayah yang berjauhan, dan dalam lingkungan yang bermacam-macam. Hal inilah yang memicu timbulnya dialek yang menyimpangi bahasa bakunya, baik yang menyimpang sedikit maupun yang menyimpang jauh dari bahasa bakunya.

Faktor kedua adalah letak wilayah Arab yang berada di persimpangan benua Asia, Afrika, dan Eropa sehingga persentuhan diantaranya sangat memungkinkan. Aspek ekonomi dapat dikatakan sebagai aspek utama. Sebagaimana diketahui bahwa Hijaz, khususnya kota Makkah sejak masa sebelum masehi telah memainkan peranan penting dalam perdagangan. Kedatangan para saudagar dari berbagai wilayah pada musim haji yang terselenggara setiap tahun memberikan andil yang besar dalam memperkaya kosa kata Arab atau mempengaruhi bahasa baku sehingga terjadi perubahanperubahan.

Faktor ketiga adalah ketika Islam berekspansi keluar negeri Hijaz yang dengan demikian membawa serta bahasa Arab bersama penggunanya. Ketika itulah bahasa Arab bertemu dengan bahasa-bahasa lain, baik yang besar seperti Persi, Hindi, Turki, bahkan Spanyol maupun yang kecil seperti bahasa suku-suku. Pertemuan dan percampuran itu melahirkan kosa kata baru yang akhirnya juga mempengaruhi struktur kalimatnya.

Faktor keempat adalah kolonisasi yang menimpa negara-negara Arab, baik pada Perang Dunia I maupun II. Para kolonialis tidak menghendaki bahasa Arab menjadi besar dan penting karena bahasa Arab identik dengan Islam. Oleh karena itu, secara tidak langsung mereka mendorong berkembangnya dialek-dialek ini menjadi alat komunikasi sehari-hari secara meluas. Artinya tidak hanya dalam suasana informal, melainkan juga dalam suasana semi formal bahkan formal.

Faktor kelima adalah luasnya wilayah negara-negara Arab saat ini yang terdiri atas 21 negara dan masing-masing terdiri atas suku yang berbeda-beda yang mempunyai kebudayaan yang berbeda-beda pula. (Hindun, 2011:5)

Faktor-faktor di atas memberi pemahaman kepada kita mengapa bahasa Amiyah itu tumbuh dan berkembang sehingga masing-masing wilayah mempunyai dialeknya sendiri.

\subsection{Perbedaan Bunyi antara Bahasa Arab Fushah dan Amiyah}

Jika dipetakan secara garis besar, bahasa Arab terbagi atas dua ragam, yakni bahasa Arab baku atau ragam standar (Fushah) atau sering disebut formal language dan bahasa Arab amiyah (bahasa sehari-hari, bahasa pasaran, atau bahasa gaul) atau sering disebut in-formal language. 


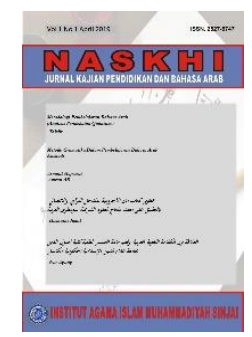

\section{NASKHI}

\section{Jurnal Kajian Pendidikan dan Bahasa Arab \\ Volume 3, No. 1, 2021}

ISSN (print) : 2527-5747

ISSN (online) : 2716-3369

Homepage : https://journal.iaimsinjai.ac.id/index.php/naskhi

Kedua jenis ini masing-masing mempunyai dialek geografis. Perbedaan dialek geografís bahasa Arab baku tidak mencolok, misalnya جdiucapkan dengan [g] di Mesir. Kata-kata dalam tuturan bahasa Arab amiyah dialek Saudi Arabia secara fonologis berbeda dengan bahasa Fushah. Hasil penelitian menunjukkan bahwa bahasa amiyah dialek Saudi Arabia mempunyai banyak variasi fonologis yang berbeda dengan bahasa Fushah. Variasi fonologis itu berupa : penggantian bunyi, penambahan bunyi, pelesapan bunyi.

1. Penggantian Bunyi

Penggantian dalam bahasa 'ammiyah dialek Saudi Arabia meliputi :

a) Penggantian konsonan dengan konsonan

Penggantian konsonan dengan konsonan pada bahasa 'ammiyah dialek Saudi Arabiah hanya terjadi pada tiga konsonan, yaitu konsonan $/ \mathrm{dz}(\dot{\jmath}) / /$ ts $(\dot{ث}) /$ dan /'a( $(\varepsilon)$.

- Perubahan /ذ/ dari [dz] $\rightarrow$ [d], Perubahan ini biasa terjadi ketika / ذ/ berposisi di akhir kata atau berada di akhir suku kata tertutup.

\section{Contoh:}

تفضل خذ [tafaddal khudz] dibaca [tafaddal khud] 'Silakan ambil'

- Perubahan /ث/ dari [ts] menjadi [t]

Contoh:

خذ في ثلاجة

ثُثاثة [tsalātsah] dibaca [talātah]

- Perubahan / $\boldsymbol{s} /$ menjadi [y]

Contoh:

ستمية سsittimi ah] dibaca[sittimiya] 'enam ratus'

b) Penggantian vokal dengan vocal

Penggantian vokal dengan vokal pada bahasa amiyah dialek Saudi Arabiah meliputi penggantian /a/ dengan /i/, dan penggantian /au/ dengan /o/ dan /ai/ dengan /e/.

Contoh:

[من أنت فmin inta] 'siapa anda?'

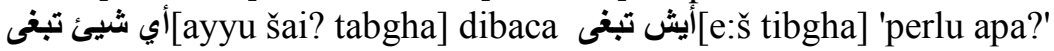

[al-tsaub] dibaca [al-tso:b] 'pakaian'

2. Penambahan Bunyi

Penambahan bunyi dalam bahasa amiyah dialek Saudi Arabia hanya ada di awal dan akhir kata, sedangkan penambahan di tengah kata tidak ditemukan.

a) Penambahan bunyi di awal

Penambahan bunyi di awal kata dalam bahasa amiyah dialek Saudi Arabia jarang terjadi. Satusatunya data yang menunjukkan adanya penambahan bunyi di awal adalah pada frase من أين؟ (min aina?] 'dari mana?'. Frase tersebut dalam bahasa amiyah dialek Saudi Arabia diucapkan من فين[min fe:n]. Di sini tambahannya berupa konsonan /f-/ yang mendahului aina.

b) Penambahan bunyi di akhir

Penambahan bunyi di akhir kata dalam bahasa amiyah dialek Saudi Arabia, yaitu penambahan vokal /a/ setelah ya' mutakallim (kata ganti orang pertama tunggal) yang berfungsi sebagai enklitik.

Contoh:

$$
\begin{aligned}
& \text { معي[ma'iy] dibaca معايا 'Bersamaku' }
\end{aligned}
$$

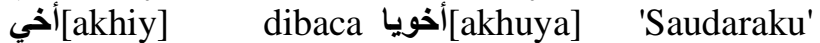

3. Pelesapan Bunyi

Pelesapan bunyi dalam bahasa amiyah dialek Saudi Arabiah meliputi pelesapan bunyi di awal, di tengah, dan di akhir kata.

a) Pelesapan bunyi di awal 


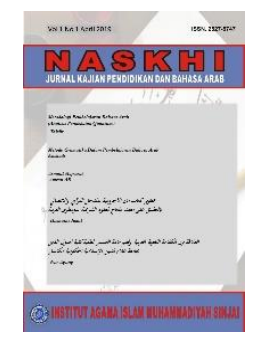

\section{NASKHI}

\section{Jurnal Kajian Pendidikan dan Bahasa Arab \\ Volume 3, No. 1, 2021}

ISSN (print) : 2527-5747

ISSN (online) : 2716-3369

Homepage : https://journal.iaimsinjai.ac.id/index.php/naskhi

Pelesapan bunyi di awal kata dalam bahasa amiyah dialek Saudi Arabia hanya ditemukan dalam dua kata, yaitu seperti contoh berikut:
خوي ليا
ريني أرني أني

b) Pelesapan bunyi di tengah

Pelesapan bunyi di tengah kata dalam bahasa amiyah dialek Saudi Arabiah ada yang berupa pelesapan konsonan dan ada pelesapan vokal.

Contoh:

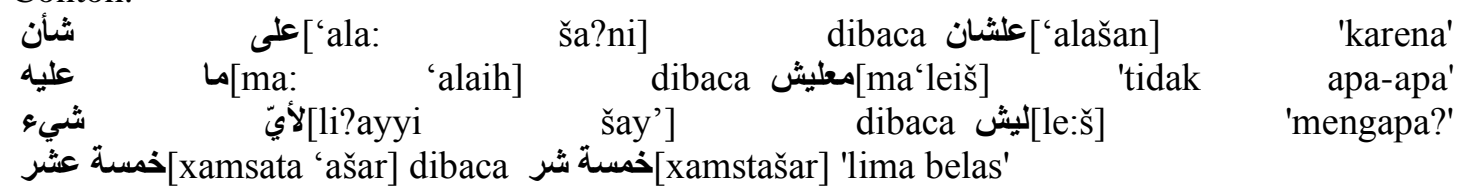

c) Pelesapan bunyi di akhir

Pelesapan bunyi di akhir kata dalam bahasa amiyah dialek Saudi Arabiah berupa pelesapan vokal, pelesapan konsonan, dan ada juga yang berupa pelesapan silabel. Pelesapan konsonan biasanya terjadi pada isim mu'annats yaitu dengan cara pelesapan konsonan $/ \mathrm{h} /$ atau $/ \mathrm{t} / \mathrm{yang}$ merupakan penanda feminin. Pelesapan vokal biasanya terjadi di akhir verba, sedangkan pelesapan silabel terjadi pada kata-kata tertentu.

Contoh:

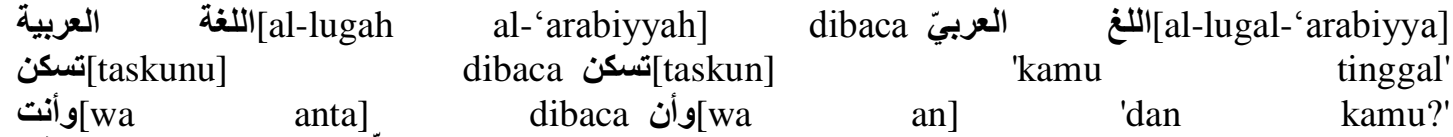

$$
\begin{aligned}
& \text { الذي الذي [al-ladzi:] dibacal-le:] 'yang (kata penghubung) (Ruhalifah, 2020) }
\end{aligned}
$$

\section{Simpulan}

Bahasa Arab Fushah adalah ragam bahasa yang ditemukan dalam al-Qur'an, hadits Nabi dan warisan tradisi Arab. Bahasa Fushah digunakan dalam kesempatan-kesempatan resmi dan untuk kepentingan kodifikasi karya-karya puisi, prosa dan penulisan pemikiran intelektual secara umum. Sedangkan Bahasa 'Ammiyah adalah ragam bahasa yang digunakan untuk urusan-urusan biasa seharihari.

Fenomena penyimpangan bahasa (lahn) adalah cikal bakal lahirnya bahasa 'Ammiyah. Istilah lahn ini dikarenakan awalnya pada kesalahan dan ketidaktaatan pada i'rab, yaitu perubahan bunyi akhir kata karena perubahan kedudukannya dalam kalimat.

Bahasa amiyah dialek Saudi Arabiah mempunyai banyak variasi fonologis yang berbeda dengan bahasa Fushah/ baku. Variasi fonologis itu dikelompokkan menjadi beberapa macam, yakni penggantian bunyi, penambahan bunyi, pelesapan bunyi.

\section{Daftar Pustaka}

Amran AR, \& Takdir. (2020). Penugasan Pembuatan Media Audio Visual Percakapan Bahasa Arab Untuk Meningkatkan Keterampilan Berbahsa Mahasiswa Pendidikan Bahasa Arab IAI Muhammadiyah Sinjai. Journal.Iaimsinjai.Ac.Id-15,(2)2, 24. http://journal.iaimsinjai.ac.id/index.php/naskhi/article/view/69

Al-Rafi' i. (1974) Tarikh Adab al-Arab, Beirut : Daar al-kitab al-Arab.

Al-Wâfi, ‘Ali ‘Abd, Fiqh al-Lughah, (Kairo: Dâr Nahdhoh Mašr li al-Tab’ wa al-Nasyr, t.t.)

Arsyad, Azhar. (2003) Bahasa Arab dan Metode Pengajarannya, Yogyakarta : Pustaka Pelajar. 


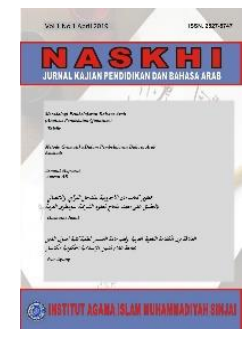

NASKHI

Jurnal Kajian Pendidikan dan Bahasa Arab

Volume 3, No. 1, 2021

ISSN (print) : 2527-5747

ISSN (online) : 2716-3369

Homepage : https://journal.iaimsinjai.ac.id/index.php/naskhi

Hindun. (2011). Pengantar Bahasa Arab Amiyah, Yogyakarta : Elisa Press.

Mahmud. (2011). Metode Penelitian Pendidikan, CV. Pustaka Setia, Bandung.

Mestika Zed. (2008). Metode Penelitian Kepustakaan, Jakarta, Yayasan Obor Indonesia.

Takdir. (2019). Metodologi pembelajaran bahasa arab (analisis pendekatan quantum ). Jurnal Naskhi: Jurnal Kajian Pendidikan Dan Bahasa Arab, 1(1), 1-7. http://journal.iaimsinjai.ac.id/index.php/naskhi/article/view/65

Sugiyono. (2012). Metode Penelitian Pendidikan. Bandung, Alfabeta.

Wafi. (1983). Al-Lughah wal mujtama', Jeddah: Syarikat Maktabah Ukadz.

Ya'kub, Emil Badi'. (1982) Fiqh al-Lughah al-Arabiyah wa Khashasuha. Beirut: Dar al-Tsaqafah alIslamiyah,

http://ruhalifah.blogspot.co.id/2013/09/perbedaan-bunyi-bahasa-arab-Fushah-dan.html, $\quad 4 \quad$ Januari 2021, pukul 11.00 Wita.

http://rinaldy-tuhumury.blogspot.co.id/2012/07/analisis-isi-content-analysis.html, 7 Januari 2021, pukul 10.15 Wita. 